\title{
PENGARUH SLEEP HYGIENE TERHADAP KUALITAS TIDUR PENDERITA DIABETES MELLITUS TIPE 2
}

\author{
Fuji Rahmawati ${ }^{1}$, Jaji ${ }^{2}$, Firnaliza Rizona ${ }^{3}$ \\ ${ }^{1,2,3}$ Bagian Keperawatan Fakultas Kedokteran Universitas Sriwijaya \\ fujirahmawati@fk.unsri.ac.id
}

\begin{abstract}
ABSTRAK
Penderita Diabetes Melitus (DM) tipe 2 memiliki gejala klinis seperti polidipsia, polyuria, dan nyeri yang juga terjadi pada malam hari dan dapat menyebabkan gangguan tidur. Bertambahnya frekuensi terbangun, susah untuk tertidur kembali, dan ketidakpuasan tidur yang menyebabkan kualitas tidur menurun adalah serangkaian akibat yang disebabkan oleh gangguan tidur. Sleep hygiene merupakan salah satu metode untuk meningkatkan kualitas tidur berupa sekumpulan daftar kegiatan yang dapat dilakukan untuk memfasilitasi mulainya tidur dan mempertahankannya. Penelitian ini bertujuan untuk mengetahui pengaruh sleep hygiene terhadap kualitas tidur penderita DM tipe 2 di wilayah kerja Puskesmas Indralaya. Penelitian ini adalah penelitian kuantitatif dengan rancangan penelitian praeksperimen dan Desain One Group Pretest Posttest. Sejumlah 29 responden dipilih untuk menjadi sampel berdasarkan kriteria inklusi. Alat ukur menggunakan kuesioner Pittsburgh Sleep Quality Index (PSQI) untuk mengukur kualitas tidur. Data kemudian dianalisis menggunakan uji wilcoxon. Hasil analisis menunjukkan bahwa terdapat perbedaan yang bermakna antara sebelum dan setelah intervensi sleep hygiene ( $p$-value $=0.000$ ) sehingga dapat disimpulkan bahwa terdapat pengaruh sleep hygiene terhadap kualitas tidur penderita DM Tipe 2. Berdasarkn hasil tersebut, perawat komunitas di Puskesmas Indralaya diharapkan dapat memasukkan sleep hygiene dalam pendidikan kesehatan yang wajib diberikan pada penderita DM tipe 2 dan keluarganya.
\end{abstract}

Kata kunci: diabetes mellitus tipe 2, kualitas tidur, sleep hygiene

\section{THE EFFECT OF SLEEP HYGIENE ON SLEEP QUALITY OF PEOPLE WITH TYPE 2 DIABETES MELLITUS}

\section{ABSTRACT}

Patients with Type 2 Diabetes Mellitus (DM) have clinical symptoms such as polydipsia, polyuria, and pain which also occur at night and can cause sleep disturbances. This sleep disturbance will increase the frequency of awakening, difficulty falling asleep again, and sleep dissatisfaction which causes the quality of sleep to decrease. Sleep hygiene is a method to improve sleep quality in the form of a list of things that can facilitate sleep initiation and maintain it. This study aims to determine the effect of sleep hygiene on the sleep quality of people with type 2 diabetes in the working area of Indralaya Public Health Center. This research is a quantitative study with a pre-experimental research design and a one-group pretest-posttest design. The sample in this study amounted to 29 respondents and was selected based on inclusion criteria. The measuring instrument used the Pittsburgh sleep quality index (PSQI) questionnaire to measure sleep quality. In addition, the data analyzed using the Wilcoxon test. The analysis results showed a significant difference between before and after sleep hygiene intervention ( $p$-value = 0.000), so it can conclude that there is an effect of sleep hygiene on the sleep quality of people with Type 2 diabetes. Based on these results, community nurses at Indralaya 
Public Health Center expected to include sleep hygiene in health education given to people with type 2 diabetes and their families.

Keywords: sleep hygiene, sleep quality, type 2 diabetes mellitus

\section{PENDAHULUAN}

Berdasarkan data International Diabetes Federation (2019) diperkirakan 463 juta (9,3\%) orang dewasa berusia 20-79 tahun saat ini hidup dengan diabetes. Jumlah diprediksi akan naik menjadi 578,5 juta $(10,2 \%)$ pada tahun 2030 dan menjadi 700 juta $(10,9 \%)$ pada tahun 2045. Jumlah kematian akibat diabetes dan komplikasinya pada 2019 diperkirakan 4,2 juta. Angka ini tentu sangat memprihatinkan dan menunjukkan bahwa penanganan diabetes harus dilakukan secara komprehensif.

Diabetes Melitus (DM) tipe 2 adalah diabetes yang paling banyak terjadi dari semua tipe diabetes (sekitar 90\%). Penderita DM tipe 2 memiliki gejala klasik seperti poliuria, polidipsia, polifagia dan penurunan berat badan secara drastis tanpa penyebab yang jelas (Soelistijo et al., 2015). Gejala klinis tersebut tidak hanya dialami pada siang hari, namun pada malam hari juga dirasakan oleh penderita DM tipe 2, hal inilah yang bisa menimbulkan gangguan tidur. Gangguan tidur adalah permasalahan universal yang terjadi pada pasien DM dan sebaliknya DM juga dapat menyebabkan gangguan tidur akibat terdapatnya keluhan nokturia serta nyeri (Suranto, 2014 dalam Tentero, Pangemanan, and Polii 2016). Bertambahnya frekuensi terbangun, susah tertidur kembali, ketidakpuasan tidur yang menyebabkan kualitas tidur menurun adalah akibat yang disebabkan oleh gangguan tidur (Kasper, Fauci, Braunwald, Longo, Jameson, dkk, 2005 dalam Gustimigo, 2015).

Pernyataan di atas didukung oleh Wahyuningsih et al., (2016) dari hasil penelitiannya bahwa sebagian besar penderita DM Tipe 2 di Puskesmas Balowerti Kediri merasakan insomnia (82,2\%). Begitu pula penelitian yang dilakukan oleh (Tentero et al., 2016) di Rumah Sakit Umum Pancaran Kasih GMIM Manado didapatkan bahwa terdapat hubungan yang bermakna antara DM dengan kualitas tidur.

Kualitas tidur diartikan sebagai suatu kondisi tidur yang dapat menciptakan kebugaran serta kesegaran pada saat terbangun bagi seseorang (Nashori \& Diana, 2005). Kualitas tidur yang buruk dapat mengakibatkan kelelahan, mudah tersinggung, mudah marah, dan depresi klinis (Khavari, 2000 dalam Muslikhatul, 2017).

Salah satu metode untuk meningkatkan kualitas tidur adalah sleep hygiene (Ahsan et al., 2015). Sleep hygiene merupakan sekumpulan daftar kegiatan yang bisa dilaksanakan untuk memfasilitasi mulainya tidur dan mempertahankannya. Komponen dalam daftar tersebut terdiri atas menciptakan lingkungan yang nyaman untuk tidur, relaksasi, makan makanan sehat pada malam hari, berolahraga, dan mengatur rutinitas jam tidur. Komponenkomponen dalam daftar ini, mendatangkan kecenderungan alami tidur menjadi bertambah dan hal yang mengganggu tidur menjadi berkurang (Butkov \& Lee-Chiong, 2007 dalam Ahsan, Kapti, dan Putri, 2015).

Tujuan dari penelitian ini adalah untuk mengetahui pengaruh sleep hygiene terhadap kualitas tidur penderita DM Tipe 2.

\section{METODOLOGI}

Penelitian ini adalah penelitian kuantitatif dengan rancangan penelitian praeksperimen dan Desain One Group Pretest Posttest. Responden dipilih sebanyak 29 menjadi sampel yang merupakan penderita DM Tipe 2 di wilayah kerja Puskesmas Indralaya. Sampel dipilih 
menggunakan teknik purposive sampling dengan kriteria inklusi. Setelah responden didapatkan, peneliti mendatangi rumah responden dan memberikan kuesioner Pittsburgh Sleep Quality Index (PSQI) yang terdiri dari 9 pertanyaan kepada responden. Setelah itu peneliti melakukan intervensi berupa Pendidikan Kesehatan tentang daftar sleep hygiene yang berisi 12 kegiatan yang perlu dilakukan untuk meningkatkan kualitas tidur. Kemudian selama tiga hari berturut-turut peneliti dibantu dengan 4 orang asisten peneliti melakukan pemantauan kepada responden sesaat sebelum jadwal tidur responden pada malam hari dengan menggunakan telepon dan video call untuk memastikan bahwa responden melakukan sleep hygiene sesuai yang telah diajarkan. Pada akhir intervensi, peneliti kemudian datang kembali ke rumah responden dan memberikan kembali kuesioner PSQI pada responden.

Analisis bivariat digunakan untuk mengetahui perbedaan kualitas tidur penderita DM Tipe 2 sebelum dan sesudah diberikan intervensi sleep hygiene. Sebelum dilakukan uji statistik bivariat, telah dilakukan uji normalitas terlebih dahulu menggunakan uji saphiro wilk karena jumlah sampel adalah $29(\leq 50)$. Hasil uji normalitas data kualitas tidur sebelum dan setelah diberikan intervensi sleep hygiene sebesar 0,023 dan 0,003 $(<0,05)$ yang dapat disimpulkan bahwa data tidak berdistribusi normal, maka uji statistik yang digunakan adalah uji wilcoxon dan didapatkan hasil $p$-value $=0,000$.

\section{HASIL}

Tabel 1. Frekuensi Statistik Kualitas Tidur Penderita DM Tipe 2 Sebelum dan Setelah Intervensi Sleep hygiene

\begin{tabular}{lcccc}
\hline \multicolumn{1}{c}{ Kategori } & Mean & Minimum & Maksimum & SD \\
\hline $\begin{array}{l}\text { Kualitas tidur sebelum intervensi sleep } \\
\text { hygiene }\end{array}$ & 9,31 & 5,00 & 19,00 & 3,63 \\
$\begin{array}{l}\text { Kualitas tidur setelah intervensi sleep } \\
\text { hygiene }\end{array}$ & 5,93 & 3,00 & 13,00 & 2,33 \\
\hline
\end{tabular}

Tabel 2. Perbedaan Kualitas Tidur Sebelum dan Setelah Dilakukan Sleep Hygiene pada Penderita DM Tipe 2

\begin{tabular}{|c|c|c|c|c|}
\hline Kualitas tidur & n & Mean & SD & p-value \\
\hline Pretest & 29 & 9,31 & 3,63 & \multirow{2}{*}{0,000} \\
\hline Posttest & 29 & 5,93 & 2,33 & \\
\hline
\end{tabular}

\section{PEMBAHASAN}

Tabel 1 menunjukkan bahwa rata-rata kualitas tidur responden sebelum intervensi sleep hygiene adalah 9,31, setelah diberikan intervensi rata-rata kualitas tidur responden meningkat menjadi 5,93 walaupun kedua nilai tersebut masih dalam kategori buruk $(>5)$.

Terdapat beberapa faktor fisik yang dapat memengaruhi kualitas tidur pada penderita
DM yaitu seringnya berkemih di malam hari (nokturia), kerap merasa haus dan lapar, gatal-gatal pada kulit, kesemutan, kram serta nyeri pada ekstremitas khususnya pada kaki (Gustimigo, 2015). Sesudah seseorang beberapa kali terbangun untuk kencing, menimbulkan sulit untuk tidur kembali. Bila kandungan gula darah di atas 160-180 mg/dl, maka glukosa akan sampai ke urine. Air tambahan akan dibuang 
oleh ginjal untuk mengencerkan sejumlah besar glukosa yang hilang apabila kandungan glukosa darah lebih tinggi lagi, akibatnya urine menjadi berlebihan sehingga penderita kerap kencing dalam jumlah yang banyak. Peningkatan jumlah dan frekuensi berkemih mengakibatkan penderita banyak minum karena mengalami haus yang berlebihan. Dengan keadaan yang semacam ini penderita sering terbangun untuk minum. Penderita juga mengalami penyusutan berat badan sebagai akibat turut hilangnya sejumlah besar kalori ke dalam urine. Untuk mengompensasi hal tersebut, penderita seringkali merasa sangat lapar sehingga banyak makan apalagi pada malam hari. Gatal-gatal pada kulit dan nyeri pada ekstremitas merupakan gejala klinis lain dari penyakit DM. Hal ini membuat penderita tidak nyaman untuk tidur dan bisa menyebabkan terbangun dari tidur (Miller \& Cappuccio, 2007 dalam Gustimigo, 2015)

Dari tabel 2 diketahui hasil uji wilcoxon kualitas tidur penderita DM Tipe 2 sebelum dan setelah intervensi sleep hygiene menunjukkan nilai $p$ value $0,000 \quad(<0,05)$, artinya ada perbedaan yang bermakna antara sebelum dan setelah intervensi sleep hygiene, sehingga dapat disimpulkan bahwa terdapat pengaruh yang signifikan sleep hygiene terhadap kualitas tidur penderita DM Tipe 2.

Seperti yang telah dijelaskan pada pembahasan sebelumnya, faktor fisik adalah penyebab utama terjadinya gangguan tidur pada penderita DM tipe 2. Namun, selain faktor fisik, ada 2 faktor lainnya yang menjadi penyebab gangguan tidur yaitu faktor psikologis dan lingkungan. Studi yang dilakukan oleh Bukit (2005) di Ruang Rawat Inap Penyakit Dalam Rumah Sakit Medan menunjukkan bahwa dari 22 responden yang ansietas, 91\% di antaranya mengalami kualitas tidur buruk, kemudian dari 37 responden yang depresi, 86\% di antaranya mengalami kualitas tidur buruk. Ansietas dan depresi bisa diakibatkan oleh rasa cemas akibat keadaan penyakit, biaya pengobatan, dan prosedur tindakan medis (Craven \& Hirnle, 2000 dalam Bukit, 2005). Menurut Miller (1995) dan Fordham (1991) dalam Bukit (2005), ansietas dan depresi bisa membuat pasien terbangun dari tidurnya, susah tertidur kembali dan bangun lebih awal.

Aspek lingkungan juga merupakan penyebab gangguan tidur yaitu: ventilasi yang tidak baik, suara/kebisingan, cahaya/lampu yang sangat terang, ruang dan tempat tidur yang kurang nyaman, dan bau yang tidak nyaman serta suhu yang terlalu panas/terlalu dingin. Hal ini sejalan dengan penelitian yang didapatkan oleh Bukit (2005) bahwa suara bising, temperatur ruangan panas, dan sorot lampu yang sangat terang merupakan penyebab umum gangguan tidur.

Ventilasi yang baik merupakan aspek esensial untuk tidur yang tenang. Supaya paruparu tidak kering, kelembaban ruangan harus diperhatikan sebab jika kelembaban ruangan tidak diatur maka seseorang tidak akan bisa tidur, meskipun bisa tidur maka seseorang akan terbangun dengan kerongkongan kering.

Tingkat suara yang dapat membangunkan tidur seseorang tergantung pada fase tidur. Suara yang rendah lebih sering membangunkan seseorang dari tidur fase 1, sementara suara yang keras membangunkan orang pada fase tidur 3 dan 4 . Level suara yang dibutuhkan agar seseorang dapat tidur dengan tenang adalah di bawah $40 \mathrm{~dB}$. Intensitas suara yang meningkat juga bisa mengakibatkan seseorang terbangun dari tidurnya (Gustimigo, 2015).

Hal lain yang juga bisa memengaruhi kemampuan untuk tidur adalah cahaya. Tingkat cahaya yang wajar ialah cahaya di siang hari lebih terang dibanding malam hari. Seseorang yang terbiasa tidur dengan suasana gelap akan mengalami kesulitan tidur apabila sorot lampu terlalu terang di ruang tidur. Ruang 
tidur adalah tempat seseorang membebaskan pikiran-pikiran yang penat atau letih sesudah seharian melaksanakan kegiatan. Jika ruang tidur kotor ataupun bau maka dapat dikatakan bahwa itulah penyabab dari sulitnya tidur. Selain itu, ruangan yang sangat panas/sangat dingin kerapkali mengakibatkan seseorang gelisah. Kondisi ini akan mengganggu tidur seseorang. Fase tidur Rapid Eye Movement (REM) menurun jika temperatur sangat panas/sangat dingin (Gustimigo, 2015).

Sleep hygiene adalah istilah yang digunakan untuk menggambarkan kebiasaan tidur yang baik yaitu dengan mengurangi faktor penyebab gangguan tidur $\mathrm{di}$ atas. Banyak penelitian yang telah mengembangkan seperangkat pedoman yang dirancang untuk meningkatkan kualitas tidur, dan ada banyak bukti yang menunjukkan bahwa strategi ini dapat memberikan solusi jangka panjang untuk gangguan tidur. Pada penelitian ini, peneliti membuat media berupa leaflet tentang daftar sleep hygiene yang berisi 12 strategi yang perlu dilakukan untuk meningkatkan kualitas tidur. Daftar ini kemudian diberikan kepada responden sekaligus dilakukan pengajaran secara detail tentang strategi sleep hygiene dan memastikan responden mampu untuk melaksanakannya.

Strategi yang dimaksud adalah mempunyai agenda bangun dan tidur yang teratur setiap hari. Catat agenda tidur klien, dan upayakan klien untuk mulai tidur pada jam tersebut. Kemudian biasakan berada di tempat tidur hanya saat tidur dan mengantuk. Upayakan klien untuk tidak melakukan kegiatan lain di tempat tidur selain untuk tidur, seperti menonton atau bermain ponsel. Selain itu, buat pikiran dan badan menjadi tenang serta rileks. Klien bisa melakukan metode relaksasi napas dalam; tarik napas melalui hidung dengan tenang perlahanlahan sambil merasakan aliran udara melewati hidung kemudian apabila dirasakan cukup udara yang dihirup, tahan sejenak lalu keluarkan napas perlahan-lahan lewat mulut. Teknik ini dapat dilakukan sebanyak lima kali. Hal ini dibuktikan oleh penelitian yang dilakukan Cahyaningsih, 2016) bahwa terdapat pengaruh terapi relaksasi nafas dalam terhadap kualitas tidur lansia.

Strategi selanjutnya adalah klien disarankan untuk tidak tidur siang lebih dari 30 menit supaya dapat menambah kualitas tidur pada malam hari. Pada saat klien mengantuk di siang hari, hendaknya lakukan aktivitas untuk mengusir rasa kantuk seperti olahraga atau berjalan-jalan. Strategi berikutnya adalah klien disarankan untuk tidak tidur dengan cahaya yang terang karena bisa membuat pikiran klien tetap terjaga, jika klien tidak terbiasa dengan kondisi gelap maka atur cahaya menjadi remang-remang. Strategi selanjutnya adalah atur suhu kamar tidur yang nyaman. Klien dapat memakai selimut tebal ketika sedang cuaca dingin, atau memakai pakaian tipis saat cuaca panas.

Strategi berikutnya adalah menjauhi suara berisik. Sebelum tidur, klien harus mematikan televisi, jika tidak dapat tidur dalam kondisi hening maka klien dapat mendengarkan musik yang lembut dengan volume yang kecil sehingga membuat klien rileks. Kemudian mandi sore dengan air hangat juga merupakan rangkaian strategi untuk meningkatkan kualitas tidur. Mandi air hangat 1-2 jam sebelum tidur sangat bermanfaat karena bisa meningkatkan temperatur badan dan bisa membuat klien mengantuk. Selanjutnya, pastikan kamar klien tidak berdebu dan menyingkirkan barang-barang yang berhamburan di sekeliling tempat tidur klien. Akan lebih baik jika memasang pengharum ruangan yang dapat membuat badan rileks.

Berikutnya adalah menganjurkan klien untuk mengkonsumsi makanan sehat dan seimbang secara teratur. Memilih makanan yang banyak memiliki kandungan serat pada buahbuahan dan sayuran, dan membatasi konsumsi 
lemak. Dianjurkan juga klien untuk tidak tidur terlalu kenyang ataupun dalam keadaan lapar, karena jika terlalu kenyang, tubuh membutuhkan waktu sekitar 2-3 jam untuk bisa tertidur dengan nyaman. Klien dianjurkan untuk tidak meminum kopi atau teh karena dapat menyebabkan tubuh dan otak tetap terjaga sehingga menghambat proses mengantuk dan semakin susah untuk tidur. Sebaliknya, terdapat beberapa makanan yang dianjurkan agar tidur lebih nyenyak, seperti susu dan madu. Susu memiliki kandungan tryptophan yaitu sejenis asam amino yang berguna meningkatkan serotonin pada otak, sehingga dapat membuat tidur lebih nyenyak (Handayani, 2020).

Klien juga disarankan untuk berhenti merokok karena dengan tidak merokok dapat membantu memperbaiki kinerja jantung dan paru-paru. Hal ini dibuktikan oleh penelitian yang dilakukan oleh Supit et al., (2018) bahwa terdapat hubungan antara merokok dengan kualitas tidur yang buruk. Strategi terakhir yaitu membuat jadwal olahraga seperti jalan kaki selama 20-30 menit setiap pagi hari. Studi yang dilaporkan pada situs Psychology Today pada tahun 2013 membuktikan bahwa olahraga yang teratur dapat meningkatkan kualitas tidur. Namun, menurut peneliti pengaruh ini baru akan dirasakan secara signifikan dalam jangka waktu yang lama yaitu setelah beberapa minggu atau bulan (Anggraini, 2018).

Pada penelitian ini, strategi sleep hygiene diajarkan dan kemudian dilakukan pada setiap responden. Hasil penelitian ini sejalan dengan penelitian yang dilakukan oleh Duman \& Taşhan (2018) bahwa latihan relaksasi otot progresif dan sleep hygiene mampu menurunkan gejala insomnia pada wanita postmenopause.

Kualitas tidur berhubungan dengan kandungan glukosa dalam darah, seperti yang diketahui, pada penderita DM Tipe 2 terjadi peningkatan kadar glukosa darah atau hiperglikemia maka penting bagi penderita DM Tipe 2 untuk tetap mempertahankan kadar glukosa darah dalam batas normal. Dalam upaya mengontrol kadar gula darah pada penderita DM Tipe 2, selain empat pilar penatalaksanaan DM (edukasi, diet, aktifitas fisik, dan farmakologi), peningkatan kualitas tidur juga merupakan hal yang penting untuk dilakukan oleh penderita DM tipe 2. Hal ini sesuai dengan penelitian yang dilakukan oleh Kalsum (2015) bahwa terdapat hubungan yang signifikan antara kualitas tidur dengan kandungan glukosa darah pada pasien DM Tipe 2 di Rumah Sakit Islam Cempaka Putih Jakarta. Fungsi sistem endokrin akan terganggu terutama terkait dengan toleransi glukosa, resistensi insulin, dan berkurangnya respons insulin apabila kurang tidur (Spiegel, 2008 dalam Kalsum, 2015).

Demikian juga penelitian yang dilakukan oleh Kurnia et al (2017) mendapatkan hasil bahwa terdapat hubungan kualitas tidur dengan kandungan glukosa darah puasa pada pasien DM Tipe 2 di RS Pancaran Kasih GMIM Manado. Tidur yang kurang bisa memengaruhi hormon pengaturnafsumakan. Apabila terjadi kekurangan tidur, kadar leptin merupakan faktor yang membuat seseorang menjadi kenyang menurun dan kadar ghrelin yang merupakan perangsang nafsu makan menjadi meningkat. Waktu tidur yang kurang juga menyababkan kesempatan seseorang untuk makan menjadi meningkat sehingga kehilangan tidur akan menambah nafsu makan dan meningkatkan asupan makan yang bisa menyebabkan berat badan bertambah dan meningkatnya kadar glukosa darah (Knutson \& Cauter, 2008 dalam Kurnia et al., 2017).

\section{SIMPULAN DAN SARAN}

Terdapat pengaruh sleep hygiene terhadap kualitas tidur penderita DM Tipe 2 di wilayah kerja Puskesmas Indralaya ( $p$-value $=0,000)$. Saran kepada perawat komunitas di Puskesmas 
Indralaya diharapkan dapat memasukkan sleep hygiene dalam pendidikan kesehatan yang wajib diberikan pada penderita DM tipe 2 dan keluarganya agar kualitas tidur penderita dapat meningkat.

\section{DAFTAR PUSTAKA}

Ahsan, Kapti, R. E., \& Putri, S. A. (2015). Pengaruh Terapi Sleep Hygiene Terhadap Gangguan Tidur Pada Anak Usia Sekolah Yang Menjalani Hospitalisasi. Jurnal Kedokteran, 6(1), 1-5. http://ejournal. umm.ac.id/index.php/keperawatan/ article/view/2846/3552

Anggraini, A. P. (2018, September 21). Mengenal Manfaat Olahraga untuk Kualitas Tidur. Kompas. https://lifestyle.kompas.com/ $\mathrm{read} / 2018 / 09 / 21 / 133220520 /$ mengenalmanfaat-olahraga-untuk-kualitastidur?page $=$ all

Bukit, E. K. (2005). Kualitas Tidur Dan FaktorFaktor Gangguan Tidur Klien Lanjut Usia Yang Dirawat Inap Di Ruang Penyakit Dalam Rumah Sakit, Medan 2003. Jurnal Keperawatan Indonesia, 9(2), 41-47. https://doi.org/10.7454/jki.v9i2.159

Cahyaningsih, A. W. (2016). Pengaruh Terapi Relaksasi Nafas Dalam Terhadap Kualitas Tidur Lansia Di Upt Wredha Budi Dharma Ponggalan Giwangan Umbulharjo Yogyakarta. E-Journal UNISA Yogyakarta, 1-15.

Duman, M., \& Taşhan, S. T. (2018). The effect of sleep hygiene education and relaxation exercises on insomnia among postmenopausal women: A randomized clinical trial. International Journal of Nursing Practice, 24(4), 1-8. https://doi. org/10.1111/ijn.12650

Gustimigo, Z. P. (2015). Kualitas Tidur Penderita Diabetes Melitus. Majority, 4(8), 133-138. http://juke.kedokteran. unila.ac.id/index.php/majority/article/ download/1487/1326

Handayani, V. V. (2020). Inilah Cara Diet Memengaruhi Kulitas Tidur. Halodoc. https://www.halodoc.com/artikel/inilahcara-diet-memengaruhi-kualitas-tidur

International Diabetes Federation. (2019). IDF Diabetes Atlas Ninth edition 2019. In International Diabetes Federation. http:// www.idf.org/about-diabetes/facts-figures

Kalsum, U. (2015). Hubungan Kualitas Tidur Dengan Kadar Glukosa Darah Pada Pasien Diabetes Mellitus Tipe 2 Di Rumah Sakit Islam Cempaka Putih Jakarta Tahun 2013. Jurnal Bidang Ilmu Kesehatan, 5(1), 233-242.

Kurnia, J., Mulyadi, N., \& Rottie, J. (2017). Hubungan Kualitas Tidur Dengan Kadar Glukosa Darah Puasa Pada Pasien Diabetes Melitus Tipe 2 Di Rumah Sakit Pancaran Kasih Gmim Manado. Jurnal Keperawatan UNSRAT, 5(1), 106524.

Muslikhatul, U. (2017). Kualitas Tidur pada Mahasiswa Pondok Pesantren. Journal of Chemical Information and Modeling, 28. http://eprints.mercubuana-yogya. ac.id/1192/3/BAB II.pdf

Nashori, F., \& Diana, R. R. (2005). Perbedaan Kualitas Tidur Dan Kualitas Mimpi Antara Mahasiswa Laki-Laki Dan Mahasiswa Perempuan. Humanitas: Indonesia Psychological Journal, 7788. http://journal.uad.ac.id/index.php/ HUMANITAS/article/view/317/209

Soelistijo, S., Novida, H., Rudijanto, A., Soewondo, P., Suastika, K., Manaf, A., Sanusi, H., Lindarto, D., Shahab, A., Pramono, B., Langi, Y., Purnamasari, D., \& Soetedjo, N. (2015). Konsesus Pengelolaan Dan Pencegahan Diabetes Melitus Tipe2 Di Indonesia 2015. In Perkeni. https://www.google.com/ 
url? sa $=$ t\& source $=$ web \&rct $=$ j \&url $=$ https://pbperkeni.or.id/wp-content/ uploads/2019/01/4. -KonsensusPengelolaan-dan-PencegahanDiabetes-melitus-tipe-2-di-IndonesiaPERKENI-2015.pdf\&ved=2ahUKEwjy8 KOs8cfoAhXCb30KHQb1Ck0QFjADe $\mathrm{gQIBhAB \& usg}=\mathrm{AOv}$

Supit, I. C., Langi, F. L. F. G., Wariki, W. M. V, Kesehatan, F., Universitas, M., Ratulangi, S., \& Tidur, K. (2018). Hubungan Antara Merokok Dengan Kualitas Tidur Pada Pelajar. Kesmas, 7(5).
Tentero, I. N., Pangemanan, D. H. C., \& Polii, H. (2016). Hubungan diabetes melitus dengan kualitas tidur. Jurnal E-Biomedik, 4(2). https://doi.org/10.35790/ ebm.4.2.2016.14626

Wahyuningsih, A. S., Huriah, T., Sari, N. K., Surya, S., Kediri, M. H., Universitas, K., \& Yogyakarta, M. (2016). Hubungan Kadar Gula Darah Dengan Insomnia pada Penderita Diabetes Melitus. The Indonesian Journal of Health Science, 7(1), 54-63. http://jurnal.unmuhjember. ac.id/index.php/TIJHS/article/view/385 